\title{
SEROLOGICAL EVIDENCE OF Rickettsia parkeri AS THE ETIOLOGICAL AGENT OF RICKETTSIOSIS IN URUGUAY
}

Ismael A. CONTI-DÍAZ(1), Jonas MORAES-FILHO(2), Richard C. PACHECO(2) \& Marcelo B. LABRUNA(2)

\begin{abstract}
SUMMARY
We report three new rickettsiosis human cases in Uruguay. The three clinical cases presented clinical manifestations similar to previous reported cases of Rickettsia parkeri in the United States; that is mild fever $\left(<40{ }^{\circ} \mathrm{C}\right)$, malaise, headache, rash, inoculation eschar at the tick bite site, regional lymphadenopathy, and no lethality. Serological antibody-absorption tests with purified antigens of $R$. parkeri and Rickettsia rickettsii, associated with immunofluorescence assay indicated that the patients in two cases were infected by $R$. parkeri. Epidemiological and clinical evidences, coupled with our serological analysis, suggest that $R$. parkeri is the etiological agent of human cases of spotted fever in Uruguay, a disease that has been recognized in that country as cutaneous-ganglionar rickettsiosis.
\end{abstract}

KEYWORDS: Spotted fever; Rickettsia parkeri; Rickettsiosis; Serology; Uruguay.

\section{INTRODUCTION}

Human rickettsiosis caused by Rickettsia parkeri, a spotted fever group agent, was first reported in the United States in 2004, 65 years after the first isolation of the agent from Amblyomma maculatum ticks in that same country ${ }^{12}$. Nowadays, $R$. parkeri is considered an emerging agent in the United Sates, with increasing reported cases since its official recognition as a human pathogen ${ }^{13}$. In addition, it is likely that a significant number of previously reported cases of Rocky Mountain spotted fever, presumably caused by Rickettsia rickettsii, were in fact caused by $R$. parkeri ${ }^{13,14}$. Besides the United States, $R$. parkeri has been reported in Amblyomma triste ticks from Argentina, Brazil, and Uruguay ${ }^{9,15,16}$. In this last country, a number of cases of rickettsiosis, often referred as cutaneous-ganglionar rickettsiosis, have been reported since 1990, characterized by a small papulo-nodular lesion at the tick attachment site, an influenza-like illness (fever, headache, malaise), and regional lymphadenopathy in all observed cases; some cases also presented generalized rash. No further clinical complication was observed ${ }^{3,4,5}$. Ticks associated with these cases were initially misidentified as A. maculatum and the rickettsial agent was prematurely identified as $R$. conorii. Subsequently, the tick species associated with rickettsiosis in Uruguay was confirmed to be A. triste (the closely related species A. maculatum is not present in Uruguay), whereas clinical and epidemiological observations have strongly indicated that the etiological agent could be $R$. parkeri, yet to be confirmed in the laboratory ${ }^{10,11,16}$. Herein, we report three new rickettsiosis cases in Uruguay, two of them with serological evidence that they were caused by $R$. parkeri after antibody absorption tests.

\section{CASE REPORTS}

Case 1: A 6-year-old male child was admitted at the hospital on 07 September 2006 with fever and a cervical lymphadenopathy. One week before, he was in contact with ticks after a visit to the Hermoza Beach area, Piriápolis, southern Uruguay. In the hospital, two ticks found attached to his scalp were collected and identified as adult females of $A$. triste. Eschars were observed at the sites of tick bites on the scalp. Oral clindamycin was prescribed, but one week later generalized rash appeared on his trunk, arms, legs, and face. Large cervical lymphadenopathy was observed. Erythromycin was prescribed and no clinical abnormalities were observed in the following week. Patient's blood serum collected two weeks after onset of fever was tested for rickettsiosis through IFA for $R$. parkeri, $R$. rickettsii, $R$. felis, $R$. amblyommii, $R$. rhipicephali, and $R$. bellii antigens, as previously described ${ }^{7,8}$. Serum end-point titers to these six antigens were 2,048, 1,024,64, 256, 512, and <64, respectively. A second serum sample collected 30 days later was tested solely to $R$. parkeri, and $R$. rickettsii, giving the endpoint titers 2,048 and 512, respectively.

Serum cross-absorption tests were performed in order to indicate the most possible rickettsial antigen responsible for inducing infection in the human patient. For this purpose, aliquots of the first serum sample were absorbed with either $R$. parkeri or $R$. rickettsii crude antigens. Production of crude rickettsial antigens was performed following a previously described protocol ${ }^{1}$, which consisted in purifying rickettsia from infected Vero cells suspended in Minimum Essential Medium (MEM) by passage through a 25-gauge syringe needle six times to lyse the cells, sequential passage of the lysate through 5 - and $2-\mu \mathrm{m}$ syringe filters to remove

(1) Department of Parasitology, School of Medicine, National University, Montevideo, Uruguay.

(2) Faculty of Veterinary Medicine, Preventive Veterinary Medicine Department, University of São Paulo, São Paulo, SP, Brazil.

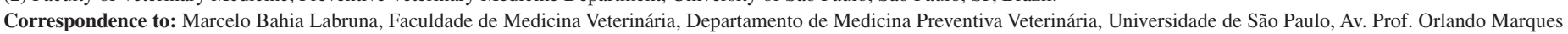
de Paiva 87, 05508-270 São Paulo, SP, Brasil. E-mail: labruna@usp.br 


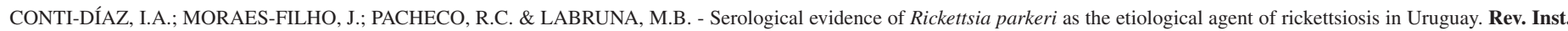
Med. trop. S. Paulo, 51(6): 337-339, 2009.

cellular debris, and centrifugation of the filtrates at $18,400 \mathrm{~g}$ at $4{ }^{\circ} \mathrm{C}$ for 20 min to pellet rickettsiae. Rickettsiae were resuspended in SFG buffer and protein concentration was determined using the bicinchoninic acid protein assay (Pierce, Rockford, IL, USA) on rickettsiae dissolved in 100

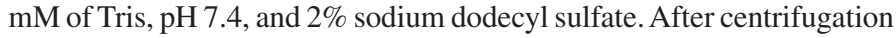
of $0.250 \mathrm{~mL}$ of purified rickettsiae, a pellet containing approximately $1.5 \mathrm{mg}$ of antigen was resuspended in $1 \mathrm{~mL}$ of the test serum at a 1:64 dilution. The serum-antigen suspension was incubated at $37{ }^{\circ} \mathrm{C}$ for four hours followed by incubation at room temperature for 20 hours on a rocker. Thereafter, the suspension was centrifuged at $13,000 \times g$ for 15 minutes, saving the supernatant that was the absorbed serum. Each of the absorbed sera was then tested by IFA to either $R$. parkeri or $R$. rickettsii crude antigens. If serum absorbed with one Rickettsia species showed no or minimal reaction against both antigens, and a strong reaction to only one of the two antigens when absorbed with the second Rickettsia species, this serum was considered to contain antibodies stimulated by the Rickettsia species (or a very closely related species) that elicited the strong reaction in the second cross-absorption and had absorbed all the antibodies in the first reaction ${ }^{6}$. After absorption with $R$. rickettsii, the serum demonstrated a 1,024 titer against $R$. parkeri and no antibodies against $R$. rickettsii, but after absorption with $R$. parkeri, there was no reaction against either of the two Rickettsia antigens. The anti-Rickettsia antibodies in this patient was considered to have been stimulated possibly by $R$. parkeri.

Case 2: In May 2007, a 57-year-old man from a rural area of Maldonado County, southern Uruguay, presented with fever and malaise. No tick bites were recorded within the previous few weeks. While living in the same rural area stated above, the patient had a history of recurrent fever, malaise, and tick bites during the previous two years, including an inguinal lymphadenopathy associated with fever in 2005. Patient's blood serum collected on May 2007 was tested by IFA, showing end-point titers of 2,048, 2,048, 64, 512, 128, and 256, for $R$. parkeri, $R$. rickettsii, $R$. felis, $R$. amblyommii, $R$. rhipicephali, and $R$. bellii, respectively. A second serum sample collected in July 2007, when patient presented no clinical abnormality, showed endpoint titers of 2,048, 1,024, 64, 256, 256, and 128 for $R$. parkeri, $R$. rickettsii, R. felis, $R$. amblyommii, $R$. rhipicephali, and $R$. bellii, respectively. Aliquots of the first serum sample were absorbed with $R$. parkeri and $R$. rickettsii antigens, as described above. After absorption with $R$. rickettsii, the serum demonstrated a 1,024 titer against $R$. parkeri, and 256 against $R$. rickettsii, but after absorption with $R$. parkeri, there was no reaction against either of the two Rickettsia antigens. The anti-Rickettsia antibodies in this patient were considered to have been stimulated possibly by $R$. parkeri.

Case 3: At 6 November 2005, a 38-year-old man from a rural area of Canelones County, Uruguay, presented with a cutaneous lesion on dorsum of the left foot secondary to tick bite suffered two weeks before. The lesion at the tick bite site was a small vesicula, which promptly became ulcerated and crusted, surrounded by a burnt reddish area, accompanied by fever $\left(37-38.5^{\circ} \mathrm{C}\right)$, painful regional lymphadenopathy, dorso-lumbar pain, and headache. Four days later, a black lesion (6-7 $\mathrm{mm}$ in diameter) of necrotic character was noted on the dorsum of left foot, encircled by a macular rounded area of 7-8 $\mathrm{cm}$ in diameter, reddish-violaceous in color, without local warm, constituted by multiple small petechial lesions (Fig.1). Edema of the foot and inflammatory lymphadenopathy at the inguino-crural zone of the same leg was also observed. On the antero-posterior areas of the trunk scarce and asymptomatic rose-colored macular lesions, $1 \mathrm{~cm}$ in diameter (rash) were present. Lyme disease was first diagnosed and oral amoxicillin at $1 \mathrm{~g}$ per day was indicated by a 7-day period, with improvement in general symptoms. Patient's blood serum collected two weeks after onset of symptoms was tested by IFA, showing end-point titers of 4,096 to either $R$. parkeri or $R$. rickettsii, and 512 to $R$. felis. No serum cross-absorption tests were done in this case. Other laboratory findings: red blood cells sedimentation rate: $35 \mathrm{~mm}$ at the first hour; red blood cells count: 4,610,000 per $\mathrm{mm}^{3}$; hematocrit: $39.3 \%$; leucocyte cells count: 7,230 per $\mathrm{mm}^{3}$; platelets: 220,000 per $\mathrm{mm}^{3}$, urine examination: normal; bacteriological examination of foot cutaneous lesion in blood agar medium: negative.

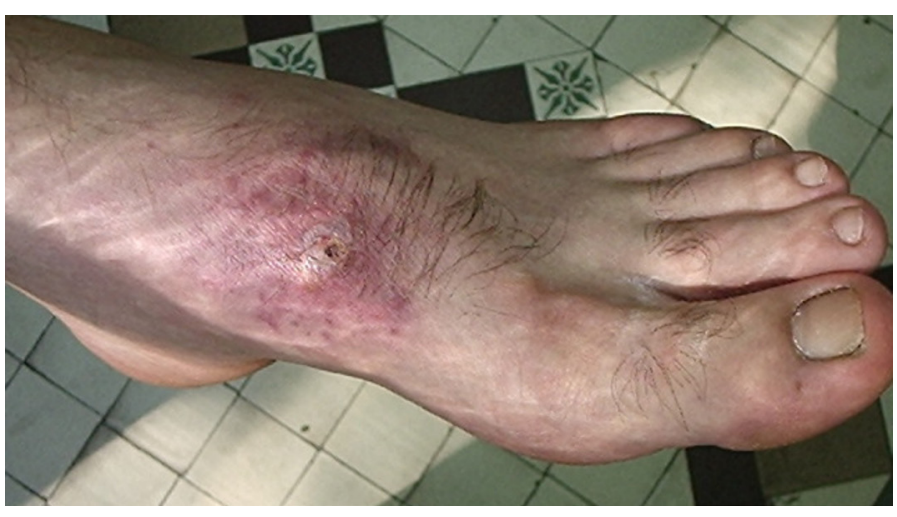

Fig. 1 - A cutaneous lesion (inoculation eschar) on dorsum of the left foot of a patient (case 3 in the text) presenting clinical cutaneous-ganglionar rickettsiosis.

\section{DISCUSSION}

The three clinical cases of rickettsiosis reported in the present study presented clinical manifestations similar to previous reported cases due to $R$. parkeri in the United States; that is mild fever $\left(<40{ }^{\circ} \mathrm{C}\right)$, malaise, headache, rash, inoculation eschar at the tick bite site, regional lymphadenopathy, and no lethality ${ }^{12,18}$. The three cases also presented similar pattern in the serological reactivities to different rickettsial antigens, characterized by higher and similar titers to $R$. parkeri and $R$. rickettsii, and substantially lower titers to other rickettsial antigens, including the spotted fever group agents $R$. felis, $R$. amblyommii, and $R$. rhipicephali. Similarly, human cases of $R$. parkeri infection in the United States showed similar IFA titers to $R$. parkeri and $R$. rickettsii ${ }^{13}$. The three patients of the present study showed clinical improvement without been treated with specific antibiotics (tetracyclines or chloramphenicol) that are usually recommended to treat rickettsiosis ${ }^{2}$. This condition is in accordance with previous reported cases of acute rickettsiosis due to $R$. parkeri in the United States, characterized by clinical manifestations that resolved even in the absence or delay treatment with specific antibiotics ${ }^{13}$.

Since no tissue sample from the patients was available in proper conditions to be tested by a direct diagnosis of rickettsia, we performed cross-absorption tests to try to indirectly identify the rickettsial agent responsible for the antibody response. In two cases, results clearly suggested that the patients were infected by $R$. parkeri. The three cases recalled previous tick infestations, but taxonomic identification of the tick was possible only in case 1 , as A. triste. Since all three cases are from southern Uruguay, where A. triste is far the most common (or the only one reported) human-biting tick ${ }^{17}$, it is quite possible that the other two cases were also related to $A$. triste infestations. Interestingly, only the adult 
stage of $A$. triste bites humans, and the seasonal activity of adult $A$. triste (August to February) coincides with seasonal increases in cases of human spotted fever reported in Uruguay ${ }^{17}$. All these epidemiological and clinical evidences, coupled with our serological analysis, indicate that $R$. parkeri is the possible etiological agent of human cases of spotted fever in Uruguay, a disease that has been recognized in that country as cutaneous-ganglionar rickettsiosis. We are aware that we can not assume with certainty that the illness observed on the three patients were due to an acute infection by $R$. parkeri because we did not show seroconversion between acute and convalescent sera, a crucial condition for proper serological diagnosis of acute rickettsiosis ${ }^{2}$. This information is particularly important in case 2, where patient history is more compatible with an acute rickettsial infection that might have occurred previous to the moment when serum was collected for analysis. Nonetheless, we present for the first time serological evidence of $R$. parkeri human infection in Uruguay. Finally, further studies with isolation and molecular identification of $R$. parkeri from Uruguayan patients will definitely confirm our findings. Since $R$. parkeri-infected A. triste ticks are also present in Argentina and Brazil, the disease will probably be diagnosed in these countries during the next years.

\section{RESUMO}

\section{Evidência sorológica de Rickettsia parkeri como agente etiológico de rickettsiose no Uruguai}

São relatados três novos casos humanos de rickettsiose no Uruguai. Os três casos clínicos apresentam manifestações clínicas semelhantes às descritas em casos de infecção por Rickettsia parkeri previamente relatados nos Estados Unidos, tais como: febre moderada $\left(<40{ }^{\circ} \mathrm{C}\right)$, mal-estar, cefaléia, exantema, escara de inoculação no sítio de fixação do carrapato, linfadenopatia regional e ausência de letalidade. Testes sorológicos de absorção de anticorpos com antígenos de $R$. parkeri e Rickettsia rickettsii, associados à reação de imunofluorescência indireta, sugerem que os pacientes de dois casos foram infectados por $R$. parkeri. Evidências clínicas e epidemiológicas, associadas com nossas análises sorológicas, sugerem que $R$. parkeri é o agente etiológico de casos humanos de febre maculosa no Uruguai, uma doença que tem sido reconhecida naquele país como rickettsiose cutâneo-ganglionar.

\section{ACKNOWLEDGMENTS}

Thanks to Prof. Eugenio Perdomo and the "Cátedra de Parasitología de la Facultad de Veterinaria de Montevideo" (Prof. Perla Cabrera ) for technical assistance, and to Cristina Sartori (Servicio Nacional de Sangre) for logistic support. This work was supported by Fundação de Amparo à Pesquisa do Estado de São Paulo (FAPESP), and Conselho Nacional de Desenvolvimento Científico e Tecnológico (CNPq).

\section{REFERENCES}

1. BALDRIDGE, G.D.; BURKHARDT, N.Y.; FELSHEIM, R.F.; KURTTI, T.J. \& MUNDERLOH, U.G.- Transposon insertion reveals pRM, a plasmid of Rickettsia monacensis. Appl. environ. Microbiol., 73: 4984-4995, 2007.
2. CHAPMAN, A.S.; BAKKEN, J.S.; FOLK, S.M. et al. - Diagnosis and management of tickborne rickettsial diseases: Rocky Mountain spotted fever, ehrlichioses, and anaplasmosis -- United States: a practical guide for physicians and other health-care and public health professionals. MMWR Recomm. Rep., 55(RR-4): 1-27, 2006.

3. CONTI DÍAZ, I.A. - Rickettsiosis por Rickettsia conorii (fiebre botonosa del Mediterráneo o fiebre de Marsella). Estado actual en el Uruguay. Rev. Med. Uruguay, 17: 119-124, 2001.

4. CONTI DÍAZ, I.A. - Rickettsiosis caused by Rickettsia conorii in Uruguay. Ann. N. Y. Acad. Sci., 990: 264-266, 2003.

5. CONTI DÍAZ, I.A.; RUBIO, I.; SOMMA MOREIRA, R. \& PÉREZ DORMIDA, G. Rickettsiosis cutáneo-ganglionar por Rickettsia conorii en el Uruguay. Rev. Inst. Med. trop. S. Paulo, 32: 313-318, 1990.

6. HORTA, M.C.; LABRUNA, M.B.; SANGIONI, L.A. et. al. - Prevalence of antibodies to spotted fever group rickettsiae in humans and domestic animals in a Brazilian spotted fever endemic area in the state of São Paulo, Brazil: serological evidence for infection by Rickettsia rickettsii and another spotted fever group rickettsia. Amer. J. trop. Med. Hyg., 71: 93-97, 2004.

7. HORTA, M.C.; LABRUNA, M.B.; PINTER, A.; LINARDI, P.M. \& SCHUMAKER, T.T.S. - Rickettsia infection in five areas of the State of São Paulo, Brazil. Mem. Inst. Oswaldo Cruz, 102: 793-801, 2007.

8. LABRUNA, M.B.; HORTA, M.C.; AGUIAR, D.M. et al. - Prevalence of Rickettsia infection in dogs from the urban and rural areas of Monte Negro Municipality, western Amazon, Brazil. Vector Borne Zoonotic Dis., 7: 249-255, 2007.

9. NAVA, S.; ELSHENAWY, Y.; EREMEEVA, M.E. et al. - Rickettsia parkeri in Argentina. Emerg. infect. Dis., 14: 1894-1897, 2008.

10. PACHECO, R.C.; VENZAL, J.M.; RICHTZENHAIN, L.J. \& LABRUNA, M.B. Rickettsia parkeri in Uruguay. Emerg. infect. Dis., 12: 1804-1805, 2006.

11. PADDOCK, C.D. - Rickettsia parkeri as a paradigm for multiple causes of tick-borne spotted fever in the western hemisphere. Ann. N.Y.Acad. Sci., 1063: 315-326, 2005.

12. PADDOCK, C.D.; SUMNER, J.W.; COMER, J.A. et al. - Rickettsia parkeri: a newly recognized cause of spotted fever rickettsiosis in the United States. Clin. infect. Dis. 38: $805-811,2004$.

13. PADDOCK, C.D.; FINLEY, R.W.; WRIGHT, C.S. et al. - Rickettsia parkeri rickettsiosis and its clinical distinction from Rocky Mountain spotted fever. Clin. infect. Dis., 47: 1188-1196, 2008.

14. RAOULT, D. \& PADDOCK, C.D. - Rickettsia parkeri infection and other spotted fevers in the United States. New Engl. J. Med., 353: 626-627, 2005.

15. SILVEIRA, I.; PACHECO, R.C.; SZABÓ, M.P.J.; RAMOS, H.G.C. \& LABRUNA, M.B. - First report of Rickettsia parkeri in Brazil. Emerg. infect. Dis., 13: 1111-1113, 2007.

16. VENZAL, J.M.; PORTILLO, A.; ESTRADA-PEÑA, A. et al. - Rickettsia parkeri in Amblyomma triste from Uruguay. Emerg. infect. Dis., 10: 1493-1495, 2004.

17. VENZAL, J.M.; ESTRADA-PEÑA, A.; CASTRO, O. et al. - Amblyomma triste Koch, 1844 (Acari: Ixodidae): hosts and seasonality of the vector of Rickettsia parkeri in Uruguay. Vet. Parasit., 155: 104-109, 2008.

18. WHITMAN, T.J.; RICHARDS, A.L.; PADDOCK, C.D. et al. - Rickettsia parkeri infection after tick bite, Virginia. Emerg. infect. Dis., 13: 334-336, 2007.

Received: 24 June 2009

Accepted: 27 October 2009 